\title{
Reasons why of nurses empaty with newborn families in neonatal ICU
}

\author{
Motivos-porque da empatia de enfermeiras com os \\ familiares de recém-nascidos em UTI neonatal \\ Razones por las que la empatia de enfermera con las \\ famílias de recién nacidas en la UCI neonatal
}

\section{Leandro Felipe Mufato ${ }^{a, b}$ \\ Maria Aparecida Munhoz Gaiva ${ }^{b}$}

\section{How to cite this article:}

Mufato LF, Gaiva MAM. Reasons why of nurses empaty with newborn families in neonatal ICU. Rev Gaúcha Enferm. 2020;41:e20190508. doi: https://doi. org/10.1590/1983-1447.2020.20190508 a Universidade do Estado de Mato Grosso (UNEMAT), Departamento de Enfermagem. Tangará da Serra, Mato Grosso, Brasil.

Universidade Federal de Mato Grosso (UFMT), Faculdade de Enfermagem, Programa de PósGraduação em Enfermagem. Cuiabá, Mato Grosso, Brasil.

\section{ABSTRACT}

Objective: To understand the empathic conduct and the reasons why nurses empathize with relatives of newborns in a Neonatal Intensive Care Unit.

Methods: Phenomenological research, performed in a hospital in Mato Grosso, Brazil. Data were collected between May and August 2018, through interviews with 11 nurses experienced in neonatal care, and analyzed through the lens of Alfred Schutz's Social Phenomenology.

Results: Presented by two categories: nurses' empathy with family members of newborns in Neonatal ICU: empathic conduct; and, the reasons why the empathic conduct of nurses with family members in neonatal ICU.

Final considerations: Empathy occurred centrally with the mother of newborns, expressed in communication, identification and construction of bonds. The reasons why the nurses' personal experiences are linked to motherhood, grief and suffering.

Keywords: Empathy. Neonatal nursing. Nurse-patient relations. Intensive care units, neonatal. Qualitative research.

\section{RESUMO}

Objetivo: Compreender a conduta empática e os motivos-porque da empatia de enfermeiras com os familiares de recém-nascidos em Unidade de Terapia Intensiva Neonatal.

Métodos: Pesquisa fenomenológica, realizada em um hospital de Mato Grosso, Brasil. Os dados foram coletados entre maio e agosto de 2018, por meio de entrevistas com 11 enfermeiras experientes em cuidados neonatais e analisados pelas lentes da Fenomenologia Social de Alfred Schutz.

Resultados: Apresentados por duas categorias: a empatia de enfermeiras com os familiares de recém-nascidos em UTI Neonatal: a conduta empática; e, os motivos-porque da conduta empática de enfermeiras com os familiares em UTI Neonatal.

Considerações finais: A empatia ocorreu centralmente com a mãe dos neonatos, expressa na comunicação, identificação e construção de vínculos. Os motivos-porque vinculam-se as experiências pessoais das enfermeiras com a maternidade, luto e sofrimento.

Palavras-chave: Empatia. Enfermagem neonatal. Relações enfermeiro-paciente. Unidades de terapia intensiva neonatal. Pesquisa qualitativa.

\section{RESUMEN}

Objetivo: Comprender la conducta empática y las razones por las cuales las enfermeras se identifican con los familiares de los recién nacidos en la Unidad de Cuidados Intensivos Neonatales.

Métodos: Investigación fenomenológica, realizada en un hospital de Mato Grosso, Brasil. Recopilamos datos entre mayo y agosto de 2018. Realizamos 11 entrevistas con enfermeras neonatales con experiencia. Analizamos los datos a través de la lente de la Fenomenología social de Alfred Schutz.

Resultados: Presentamos dos categorías: empatía de las enfermeras con los familiares de los recién nacidos en la UCIN: conducta empática; y, las razones por las cuales la conducta empática de las enfermeras con los miembros de la familia en las UCIN.

Consideraciones finales: La empatía se produjo centralmente con la madre de los recién nacidos, expresada en comunicación, identificación y construcción de vínculos. Las razones por las cuales están vinculadas las experiencias personales de la enfermera con la maternidad, el dolor y el sufrimiento.

Palabras clave: Empatía. Enfermería neonatal. Relaciones enfermero-paciente. Unidades de cuidado intensivo neonatal. Investigación qualitativa. 


\section{口INTRODUCTION}

Empathy has been the subject of studies in the health field, especially in fields of knowledge such as psychology, medicine and nursing, in a search to better understand the interaction between professionals and their patients. There is a growing number of scientific publications on empathy, showing a current and global concern on this topic in health and philosophy ${ }^{(1)}$.

In the context of research on health empathy, there is a need to consider it as an approach that values the subjective and social aspect of the professionals' attitudes in order to better understand what makes them more empathic ${ }^{(2)}$.

In the nursing area, concepts and explanations about empathy that are more appropriate to the nurse's work process have been proposed, with emphasis on the notion that empathy occurs: incidentally - depending on the context that allows the professional to be empathetic, as a way of knowing - which supports the theory that empathy improves access to patients'needs, as a process - demonstrating that empathetic nurses are empathetic at different times and repeatedly, and, as a way of being a nurse - showing that empathy is a proper way of exercising the nursing profession ${ }^{(3)}$.

Empathy is present in when the nursing professional/ nurse meets the newborn and his family in Neonatal Intensive Care Units (NICU). In this care context, it can improve the perception of the family's needs, the establishment of a bond between families and professionals, and increase the parents confidence in caring for their hospitalized child(4).

Social interactions between nurses and family members are taking place in the NICU environment, where the presence and participation of the family in the care of premature newborns is a fundamental factor, intrinsic to the best results in neonatology. This demonstrates the importance of qualifying professionals in this area to deal with families in this space, to know their vulnerabilities, to identify their needs, and to relate to them in a way that is welcoming. In this context, the professional nurse has a prominent role in articulating care between families and newborns. Communication and empathy are essential tools in this process ${ }^{(5)}$.

Despite the importance of empathy for nurses working in neonatal units, little has been discussed in the literature how this sentiment is experienced by these professionals in relation to the family members of newborns hospitalized in the NICU. Furthermore, investigating what leads them to be empathic with the families of these NBs can help elucidate how empathy occurs in a professional setting, contributing to the understanding of the phenomenon of empathy, of utmost importance for humanized nursing care in $\mathrm{NICUs}^{(6)}$.
This context provokes an approach to empathy considering it as a nurse's conduct in their work when caring for newborns in the NICU, and to investigate the ways in which it occurs, and the reasons why it occurs with the relatives of these hospitalized babies. The research is based on the following guiding question: How do nurses empathize with the relatives of newborns in the NICU, and for what reasons? Thus, the objective of this study was to understand the empathic conduct and reasons why nurses' empathy with the relatives of newborns in the NICU.

\section{METHODOLOGY}

Text extracted from the Ph.D. Thesis in Nursing titled "NICU nurse empathy."This excerpt takes place as a phenomenological study supported by Alfred Schutz'theoretical-methodological framework. This study adopted phenomenology as a theoretical-methodological approach, as it allowed to deepen the intersubjective dimension of nursing care.

Phenomenology makes it possible to understand the life experiences related to care from the professionals' perspective. This research approach is increasingly used by nursing and contributes to investigations about more humanized care $^{(7)}$. Applied to the focus of our research, it allowed us to study nurses' understanding of empathy and to analyze the experiences that emerge as the reasons or justifications of this action.

Phenomenology investigates experiences, that is, not the world that exists, but the way in which the knowledge of that world is conceived by the conscience, therefore, revealing the experience of the person being investigated ${ }^{(8)}$. The meaning that experiences acquire for a person is the code they use to interpret the world in which they live. This can be explained by the notions of "determined biographical situation" and "stock of knowledge"(9).

Every person always has their biographical situation determined. This implies that their environment is historically constructed, within which the person has a physical, social, moral and ideological position. The stock of knowledge exists in the continuous flow of your consciousness and changes from an experience (now) to a new experience (new now). Thus, it changes in length and structure as new experiences take place. The new experiences happen as an "equal that is repeated" or an "equal that is modified", and expands ${ }^{(9)}$.

When man remembers his experiences, he casts his intentionality into the past, cutting out and highlighting an experience in his continuous flow of consciousness. The retained experience, in the light of intentionality, acquires meaning through reflection. It is in retrospect of his own action that the context of meaning context in which the motives for the action are found ${ }^{(10)}$. 
In an action, common language usually assigns an objective, "did this for the purpose of." However, the motivation for the action is in relation to the past experiences of those who carried it out, and future experiences as well. The real reasons-why are the agent's antecedent experiences, which they turn to after the action is performed, and which, for them, are in a context of meaning as experiences that motivate the action. The reasons-why are the action motivators, which explain the project of the action itself ${ }^{(9-10)}$.

The person is not aware of the reasons-why (which are related to their past experiences and which determined that they acted as they did) at the time of the action. Only after the action is performed can we turn to it in the past, and as observers of ourselves, reflect on the circumstances that led us to do what was done, to act as we $\operatorname{did}^{(9-10)}$.

The setting for this study was the NICU and the Neonatal Intermediate Care Unit (UCIN), of a University Hospital, located in the city of Cuiabá, Mato Grosso, Brazil. The service has 10 intensive beds and 05 semi-intensive beds in neonatology.

The inclusion criteria encompassed people who could be informants in the research: nurses with experience in neonatal care for more than six months. We used the criterion of the power of the information collected in the interviews to end the fieldwork ${ }^{(11)}$. This criterion judges aspects of the qualitative study and its conduct by the researchers to assist in observing the achievement of the objectives, such as: the objective of the study - broad or specific; sample specificity - dense or sparse, establishment of a theory - applies or not, quality of dialog - strong or weak, strategy analysis - case or segment of cases. Eleven nurses were interviewed.

The interviews followed the recommendations of the phenomenological approach in research ${ }^{(8,12)}$. The place where the interviews were conducted was chosen by the participants, ten of which took place in hospital rooms previously scheduled, and one of them took place at the nurse's home. The interviews were recorded on a digital audio recording device for subsequent transcription. The duration ranged from forty minutes to two hours and forty minutes. They started with the following guiding question: Tell me what you have experienced regarding empathy in caring for babies and their families? Data was collected from May to August, 2018.

Based on Alfred Schutz's theoretical framework of Phenomenology, we performed the data analysis describing these nurses' experiences of empathizing with the family members of the NBs hospitalized in the NICU, as well as the reasons why the actions were interpreted by them as empathy.

This research complied with all ethical principles, in accordance with Resolution No. 466/2012 of the National Health Council, and approved by the Research Ethics Committee
(CEP) with Human Beings, Opinion No.2,624,217. All participants signed a free and informed consent form (FICF) to use the data. The names of the participants were replaced by the letter " $E$ ", and differentiated from one interview to another using the sequence E1,E2, E3, ... successively.

\section{口ESULTS}

\section{The empathy of nurses with family members of newborns in the NICU: empathetic conduct}

The interviews showed that understanding that NICU nurses have about the empathetic conduct with the relatives of hospitalized newborns. These conducts were communicating with the parents, with emphasis on the moment of their first visit to the child and the welcoming, the dialog about the parents' doubts and fears during hospitalization, better knowing the family's needs, building bonds with the mothers who transcended the hospitalization period, and the identification between nurses and mothers due to similar experiences between them, such as the loss of a loved one and motherhood. In addition, empathy appears as something to be avoided in the experience of one of the nurses in this study. The centrality of the figure of the mother as the relative with whom nurses interact the most is recurrent.

There is an emphasis when communicating with parents at a given time, the welcoming, which is the parents' first contact with the NICU. Let's see:

[...] the father arrives all apprehensive and wants to know how his son is doing. So, we give them an initial greeting. [...] When they arrive, they just stand there looking at the baby in the incubator, with all those tubes. (E1)

I think there is this moment ofempathy. I find this important. I think it begins at the greeting. Empathy is important from the moment you greet them. (E8)

For me, empathy begins when this mother enters the neonatal center. [...] it's watching the mother come in, greeting her, taking her to her child's incubator. And, giving her all the information you can. (E7)

Communicating with parents, in the sense of being empathetic, also appears in addition to greeting the parents' at the time of their first visit to the NICU. The nurse reports empathy in the conversation with mothers in their daily work, when the focus is on guiding those who still have doubts:

Forme, it means talking to everyone [...] Then the mothers come in and I go talk to them. I just walk by talking to 
everyone. I check up on them to see who's been instructed on what the NICU routine is like [...] There are always questions (E4)

Empathy can be interpreted as building a bond with the mothers of newborns. A bond that can surpass the baby's hospitalization, as observed in this statement:

So we create a... We talk a lot. The mother's usually become Facebook, whatsapp friends. They send us pictures of the baby frequently. The mothers come to the clinic just to say hi to people. I went to a birth day party for one of the babies. (E10)

Another meaning given to empathetic conduct is to better understand the needs of families, especially social needs. Empathy emerges as a desirable characteristic for nurses working in neonatology, as it allows them to better understand these needs.

You think "what if it was you?" If it were your child, how would you like the assistance to be? [... all areas are especially important, butfor the neonatal, because of the father, the parents, the family members themselves, it is particularly important. [... you also end up being more moved by that mother, that family. More humble... anyway. And then, that's when you must have that different view. (E6)

The identification between the nurse and the mother of a newborn admitted to the NICU also emerges as empathy in the interviews. Similar life experiences generate this identification between them. The experience of being a mother or losing a loved one can be something in common. For example:

It's one thing for you to imagine someone's suffering, another thing for you to have gone through the same situation as them. [...] My suffering means that I can have an idea... Of how hurt the other person is. (E11)

[...] You only know what a person is going through if you've experienced a situation. Motherhood is not easy for women. [...] So, this is how we mothers relate to each other. It is difficult to have a conversation with someone who is not a mother. It seems that you speak the same language (laughs). They say: "Nurse, are you a mother too?"I say "l am". (E11)

Actions said to be empathic are also strategically avoided by the nurse when it becomes an emotional involvement that causes emotional exhaustion, as in this case:
I'm unable to be at ease with the companion in the ICU [...] I avoid it. [...] Even though we have a good relationship with the companion, the mother, father, grandparent, I avoid it regardless. I avoid that contact [...] I try to distance myselffrom the parents because of that. It's just too much pain. It's exhausting, you know? We deal with suffering. It's just not easy. (E2)

\section{The reasons-why for nurses' empathetic conduct with family members in the NICU}

The reasons why these nurses' empathetic behaviors help us to understand the different meanings expressed. Part of the nurses'stock of knowledge and past experiences emerge in this sense.

Regarding getting to know stories of those mothers during their work, one nurse mentioned her own experience as a mother, when at the time of the birth of her daughter she was separated from the baby for twenty-four hours, without knowing where her daughter was. The importance of, now as a nurse, addressing mothers' doubts emerges in her speech:

Iremember them saying: "No! Isn't there a way you could..." "I'm sorry, mommy, there isn' $t$ " (imitates the way the person who forbade her from seeing her daughter spoke). That hurt! I remember it to this day (it seems the word "mommy" made her remember the episode with anger). "There's no way you can... Because the baby's in the incubator, with oxygen." I didn't even know what that was! I had no idea what an incubator was. [...] I think that... I think that influences my position and attitudes today. When I began working in the health field, I started thinking. I began to think critically, seeing what it's like? [...] it can even be a ... I can put myself in the other mother's shoes. I see the babies in the incubator and I look at it like "It feels so good to give them information." (E4)

About having a special focus on the family's social issues, mobilizing to help the less fortunate family, what draws her attention the most, the nurse brings to mind examples of professionals, nurses, who taught her when she started working in neonatology:

I mirror the nurse who trained me. She did this. She got involved. She would help the mother with transportation fees so she could see her baby. "I can't come back tomorrow." "Yes you can. Here!" She would take the money from her own so the mother could see her child. You could see the family had no second intentions, they simply couldn't afford it sometimes. And it happened a lot. (E6) 
For one of the nurses, the before and after the birth of the child, is memorable in her interview for the research. The influence of the experience of being a mother is also present for other nurses in the study:

Being a mother changed me. [...] before becoming a mother: I was more technical, more agile, job-workhome, you know. [...] After becoming a mother, none of my strategies worked, you know? [...] How many changes have taken place in my life? And I started to humanize my thoughts more. (E7)

I always say I'm going to involve motherhood in this. Because after the woman is a mother, she changes in that sense too. I changed a lot after my daughter. [...] I started to sympathize ... Be more supportive of the person. I say I was more mechanical before. I arrived, I did my more technical work, but not today, after motherhood. (E10)

The experience of losing a loved one takes center stage in the experience of a nurse's empathy, about which she describes her pain and how this experience makes her understand the reality she experiences today, with mothers in the NICU:

I'll give you an example. I lost my father. [...]. When he died, I thought I would never experience that situation in my life. Boy... It was such a huge pain, but so great, that my heart hurt. [...] I thought I was having a heart attack. [...]. And in my experience of this loss, I related the mothers' pain a lot. It really hurts. It hurts too much to lose someone awfully close. (E11)

When stating that empathy needs to be avoided, the nurse explains the pain and suffering that the hospital discharge outcomes bring her, and especially the babies' deaths and the mothers' suffering. She tells the story of a young mother who lost her daughter:

She put the girl to bed and said ... (case of the mother who lost her daughter, a six-month-old girl, was already dead in this narrated scene) She turned to everyone, everyone was around her, and she said: 'thank you very much, I know you did everything you could. Then she hugged her and said: 'mommy will never forget you, even though I'm young, and still have a life, and have other kids, I'll neverforget you.' I neverforgot that. [...] There's no reason for getting involved, you know. Like, you already have all your everyday problems, and it's... for what? (E2)

Figure 1 shows the synthesis of the study's findings, correlating empathic conduct in the way it was understood by nurses and past experiences that make them interpret empathic conduct.

Flow of conscious of nurses' awareness over the time of their

\begin{tabular}{|c|c|c|c|}
\hline 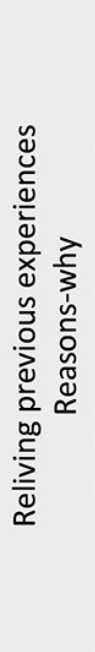 & $\begin{array}{l}\text { - Experience of being a } \\
\text { - Experience of having a daughter } \\
\text { hospitalized in the NICU } \\
\text { - Experience of learning with } \\
\text { empathic nurses } \\
\text { - Experience of losing a loved one } \\
\text { - Experience of suffering with the } \\
\text { loss of a NB in NICU }\end{array}$ & 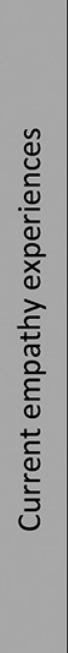 & $\begin{array}{l}\text { - Communicate with parents on } \\
\text { the first visit to the newborn } \\
\text { Building a bond with mothers beyond } \\
\text { the length of hospital stay } \\
\text { - Dialoging and resolving the } \\
\text { doubts of mothers } \\
\text { of families } \\
\text { - Relating to mothers in } \\
\text { experiences of loss } \\
\text { - Avoiding attachment to the } \\
\text { parents of hospitalized newborns }\end{array}$ \\
\hline & & & Present \\
\hline
\end{tabular}

Figure 1- Reasons why for the empathy of nurses with family members of newborns hospitalized in the NICU Source: Research data. Author himself. 


\section{DISCUSSION}

There are some reasons-why, such as previous experiences, which, when recalled, provide the context for the interpretation and motivation of nurses' current experiences of empathy. And, these understandings come in part from their own experiences of being a mother, death of a loved one, suffering, grief, death of hospitalized NBs and professional examples throughout their careers.

Regarding the nurses' understanding of empathic conduct with the mothers of hospitalized NBs, we observe the centrality in communicating, answering question, creating bonds and identifying with these mothers. Nurses have already pointed out empathy to care for their patients in a comprehensive and individualized way, something fundamental for humanized NICU care. Thus, welcoming the family and inserting them in care is a way of understanding that care is empathic and humanized ${ }^{(13)}$.

For the mothers of NBs, the experience of having a child hospitalized, together with the lack of knowledge about what a NICU is like, causes fear, anxiety and sadness for not taking the child home as planned, feeling guilty and terrified $^{(14-15)}$. Therefore, the experiences of empathy reported in our study, when associated with communicating with mothers, demonstrate the importance of these actions in face of the negative feelings they may experience with the admission of a child to the NICU.

A different outline of these actions is in the negative meaning that empathy received in one of the studied experiences, when the nurse avoids dialog with the parents, whose presence as companions bothers her. Even in this negative experience, it is the involvement with the parents, through dialog and knowing their stories, that are being placed as an aspect of the experience in the empathic experience. This difference in the meaning granted to understanding through the experience of a nurse's empathy reveals that the emotional demand and the needs of mothers who have their children admitted to the NICU are received in different ways, depending on the professional.

Someone's action, for the observer, has an objective meaning, which differs from the subjective meaning for the acting agent who performs it ${ }^{(10)}$. We emphasize that communicating, conversing, giving guidance, welcoming and interacting are objective actions for those who see them as an observer, but it carries own motivations and subjective meanings for the acting agent, the nurse.

Experiences build man's stock of knowledge and direct his interpretation of his actions, the genuine reasons-why $y^{(10)}$. Thus, the reasons-why of an action can give the meaning of the experience, as being positive or negative for these nurses. The nurse's previous experiences set the tone for how current actions are interpreted, demonstrating how each of them sustains its own way of acting in interactions with family members.

Of the family members, the mother figure occupies the main role in how interactions and empathic experiences take place for the nurses, regardless of the presence or absence of parents in the NICU. Part of the structure of the empathy experience, for these nurses, was linked to the similarity of past experiences, such as being a mother, for example.

These antecedent experiences somehow typify the social interactions experienced in the new now ${ }^{(9)}$, which influences the interactions between nurses and mothers. The experience of the nurse's involvement with the mother, followed by death and mourning, typifies the current interaction with mothers as an "equal that is repeated", that is, as a path to the loss, mourning and suffering lived in the previous experience. The nurse retained the experience in memory, has it in her stock of knowledge, in which this becomes a recipe for how to act in a certain typified situation: the interaction with newborns and their parents in the NICU. This reveals a negative side of empathy as a form of emotional involvement between a nurse and the mother of a newborn hospitalized in the NICU.

We suggest carrying out further studies on the experiences that consolidate an interpretation of interactions in the NICU as something negative, as they are also experiences that generate defense mechanisms against suffering, such as mechanized and strictly technical assistance. The number of NICU nurses who report fatigue out of compassion is high, and the death of a newborn hospitalized for long-term is one of the factors that influence this secondary traumatic stress experienced by the nurse ${ }^{(16)}$.

As for the experience that leads the nurse to dialog with the mother to answer her questions, there is a typical recipe in her knowledge store for typical cases of hospitalization and separation between newborns and mothers, and how much they lack information. This context gives motivational meaning for her to interpret that it is important to offer information, so that mothers have no doubts about touching, being together and taking care of their children hospitalized in the NICU.

The experience of being a mother, giving birth, becoming a mother, and taking care of a child influences how the nurse sees and interprets the NICU mothers, and is part of the structure of the nurses' empathy experience in this care context. We observed that the previous experience of being a mother left the nurse more sympathetic to the mothers of the NICU. 
Literature has already revealed that neonatal nurses who had their children admitted to the NICU undergo a change in the way they see the mothers with whom they work. Nurses who became mothers of babies who needed to be admitted to the NICU and then returned to work with hospitalized babies, can come to understand the importance of spending time talking to mothers, touching babies, teaching them to care, and having someone from the health team to defend their causes, their complaints ${ }^{(17)}$. Our findings suggest that empathy with mothers in the $\mathrm{NICU}$ is not exclusively influenced by the nurse's previous experience of having a child admitted to the NICU, but by the experience of being a mother, of losing a loved one, of grieving together with a mother during work and also of having examples of empathetic nurses throughout their training in neonatology.

The experiences of the nurse who works in neonatology that came from the professional field were not presented to us in relation to the fact that they are empathic. The closest we got to having examples that taught how to be empathetic was when the nurse was already trained. She reports that she learned to have a more sensitive look at the needs of families with the nurse who trained her, at the beginning of her career.

We did not analyze the training of nurses who participated in this study, but no case of empathy occurred as a result of something they learned in training, there were no examples of teachers, nor reports of some learning during training that could have made it possible to value empathy. This absence of training as an influencer of empathy was noticed by us. There is evidence that training can improve nursing students'empathy rates ${ }^{(18)}$. However, it is necessary to develop new research that explores how training influences nurses' empathy after graduation.

There is a lack of clarity about the role of knowledge, such as that of Social Sciences, in the training of nurses, which devalues the theme, "which is of fundamental importance for the holistic critical thinking of graduates of undergraduate nursing courses" ${ }^{\prime \prime(19: 2194) \text {. }}$

If we focus on these findings, we will balance these experiences and see the high weight that personal experiences have when it comes to being sensitive to the condition of mothers in the NICU, in the sense of acting empathetically. And. the low weight that professional experiences have on this scale in influencing empathy, and the zero weight of nursing training with a view to being an empathic nurse.

\section{FINAL CONSIDERATIONS}

The nurses participating in this study reveal their understanding of what empathic conduct with family members of newborns hospitalized in the NICU means. In the description of these experiences, we found the centrality of the newborn's mother as the relative related to the nurses'empathy. In addition, empathy centered on communication, dialog, welcoming, knowledge of the social needs of families and identification between nurses and mothers.

The reasons why nurses' empathy with family members of hospitalized NBs are revealed in the previous experiences of nurses in their own maternity, regardless of whether the child needs hospitalization in the NICU, in addition to the experience of suffering, grief, loss of loved ones and having learned about neonatal nursing with empathic nurses. In addition, it revealed a context of meanings that motivate the avoidance of parents in the NICU, arising from their own professional experience of involvement with family members when the hospitalized newborn progresses to death.

These findings contribute to understanding more about the subjectivity of nurses' work in the NICU in the context of their interaction with the mothers/family members of NBs, something that expands the knowledge regarding health care humanization in this professional care scenario. It also contributes to understanding some important aspects of the empathy of female professionals, and the social aspects regarding empathy in the health field that still need to be better explored. The absence of experiences from training was highlighted, which points to a criticism of the way we demand humanized professionals without, to some extent, training them to be empathic.

Suggestion is made to develop new studies in relation to the influence of personal and professional antecedent experiences on empathy, and in relation to gender, as the female experiences of motherhood influenced the empathy studied here. The understanding of the participating people as subjects situated biographically, and who use a stock of knowledge arising from their experiences to act in the world of life, contributed to the results we achieved. The adaptability of these findings also needs to be explored in future research.

This study has limitations when performed with people who carry homogeneous characteristics, such as gender, all women, with experiences in neonatal care at a single hospital. We suggest the development of new studies with nursing professionals, in addition to different neonatal care scenarios, which may differ in their institutional philosophy on this aspect of care, something that may contribute to 
other reasons for empathic conduct not yet explored by our study, or present in the literature.

\section{REFERENCES}

1. Mufato LF, Gaíva MAM. Empathy in health: integrative review. Rev Enferm Cent. Oeste Min. 2019;9:e2884. doi: https://doi.org/10.19175/recom.v9i0.2884

2. Mikkonen K, Kyngäs H, Kääriäinen M. Nursing students' experiences of the empathy of their teachers: a qualitative study. Adv Health Sci Educ Theory Pract. 2015;20(3):669-82. doi: https://doi.org/10.1007/s10459-014-9554-0

3. Wiseman T. Toward a holistic conceptualization os empathy for nursing practice. ANS Adv Nurs Sci. 2007;30(3):e61-e72. doi: https://doi.org/10.1097/01. ANS.0000286630.00011.e3

4. Ferreira JHP, Amaral JJF, Lopes MMCO. Nursing team and promotion of humanized care in a neonatal unit. Rev Rene. 2016;17(6):741-9. doi: https:// doi.org/10.15253/2175-6783.2016000600003

5. Gomes DF, Moita MP, Dias MAS, Fernandes MC, Diniz UL. Papel do enfermeiro no cuidado intensivo neonatal no Brasil. Essentia (Sobral). 2019 [cited 2019 Dec 19];20(1):9-16. Available from: http://essentia.uvanet.br/index.php/ revistaessentia/article/view/239

6. Salazar OAB. Humanized care: a relationship of familiarity and affectivity. Invest Educ Enferm. 2015;33(1):17-27. doi: https://doi.org/10.17533/udea.iee. v33n1a03

7. Núñez CAS, Celis IEV. La Fenomenología de Husserl y Heidegger. Cult Cuid. 2017;21(48):43-50. doi: https://doi.org/10.14198/cuid.2017.48.05

8. Padoin SMM, Terra MG, Paula CC, Langendorf TF, Siqueira DF, Motta MGC, et al. Pesquisa qualitativa apoiada no referencial teórico da fenomenologia. In: Lacerda MR, Ribeiro RP, Costenaro RGS. Metodologias da pesquisa para a enfermagem e saúde: da teoria à prática. 1. ed. Porto Alegre: Moriá; 2018. p. 233-262.

9. Schutz A. Fenomenologia e relaçōes sociais. Rio de Janeiro: Vozes; 2012.
10. Schutz A. A construção significativa do mundo social: uma introdução à sociologia compreensiva. Rio de Janeiro: Vozes; 2018.

11. Malterud K, Siersma VD, Guassora AD. Sample size in qualitative interview studies: guided by information power. Qual Health Res. 2016;26(13):1753-60. doi: https://doi.org/10.1177/1049732315617444

12. van Manen M. Researching lived experience: human science for an action sensitive pedagogy. 2nd ed. London, New York: Routledge; 2016. E-book

13. Dias IMAV, Fialho FA, Silva LR, Santos RS, Salvador M. Tecnologias aplicadas pela enfermagem no cuidado neonatal. Rev Baiana Enferm. 2015 [cited 2019 Dec 17];29(1):23-32. Available from: https://portalseer.ufba.br/index.php/ enfermagem/article/view/12309

14. Ued FV, Silva MPC, da Cunha ILR, Ruiz MT, Amaral JB, Contim D. Perception of mothers when visiting their child in the neonatal unit for the first time. Esc Anna Nery. 2019;23(2):e20180249. doi: https://doi. org/10.1590/2177-9465-ean-2018-0249

15. Tronco CS, Rodrigues AP, Paula CC, Souza IEO, Padoin SMM. The significance of a newborn stay in the ICU after the mother's discharge: a Heideggerian phenomenological study. Cienc Cuid Saude. 2018;18(3):e45015. doi: https:// doi.org/10.4025/cienccuidsaude.v18i3.45015

16. Beck CT, Cusson RM, Gable RK. Secondary traumatic stress in NICU nurses: a mixed-methods study. Adv Neonatal Care. 2017;17(6):478-88. doi: https://doi. org/10.1097/ANC.0000000000000428

17. Fishering R, Broeder JL, Donze A. A qualitative study: NICU nurses as NICU parents. Adv Neonatal Care. 2016;16(1):74-86. doi: https://doi.org/10.1097/ ANC.0000000000000221

18. Bas-Sarmiento P, Fernández-Gutiérrez M, Díaz-Rodrigues M, iCARE Team. Teaching empathy to nursing students: a randomised controlled trial. Nurse Educ Today. 2019;80:40-51. doi: https://doi.org/10.1016/j.nedt.2019.06.002

19. Riegel F, Crossetti MGO, Siqueira DS. Contributions of Jean Watson's theory to holistic critical thinking of nurses. Rev Bras Enferm. 2018;71(4):2193-9. doi: https://doi.org/10.1590/0034-7167-2017-0065

\section{- Corresponding author:}

Leandro Felipe Mufato

Email: leandro.mufato@gmail.com

\section{Associate editor:}

Carlise Rigon Dalla Nora 